\title{
内部圧力を考慮した血管の高速変形手法
}

\section{A Fast Blood Vessel Deformation Method Considering Inside Pressure}

\author{
中川真志 ${ }^{\dagger}$, 正会員 向井信彦 ${ }^{\dagger}$, 正会員 小杉 信 ${ }^{\dagger}$ \\ Masashi Nakagawa $^{\dagger}$, Nobuhiko Mukai ${ }^{\dagger}$ and Makoto Kosugi ${ }^{\dagger}$
}

\begin{abstract}
This paper describes a fast deformation method for blood vessels, in which there are blood streams. It takes a long time to analyze liquid behavior on the basis of the Navier-Stokes equation, so our method uses Boyle's law, which defines the relationship between volume and pressure for gas. Blood is incompressible, while gas is compressible. We then consider quasi-pressure when a blood vessel is shrunk by an external force, and restore the volume of the blood vessel by using the quasi-pressure. As a result, the volume of blood vessels could be kept constant and our method satisfies the incompressible condition of blood. Finally, the proposed method has enabled us to deform blood vessels very fast compared with the fluid dynamics method based on the Navior-Stokes equation.
\end{abstract}

キーワード：コンピュータグラフィックス，バーチャルリアリティ，手術シミュレータ，質点バネモデル

\section{1. ま え が き}

近年，医療技術の進歩により内視鏡等を用いた低侵襲 手術が盛んに行われているが，これらの新しい技術を修 得し, 安全かつ正確な手術を行うには数多くの訓練が必 要である，そこで，バーチャルリアリティ(VR) 技術を応 用することにより, 高度化する手術手技に対する有効な トレーニング装置としての手術シミュレータが期待され ている。また，手術シミュレータは手術練習以外に，医 療教育の効率化, 術前計画による手術の安全性と成功率 の向上, 家族や患者本人に対する手術の説明と同意 (イ ンフォームドコンセント) の支援という側面も期待され ている.

これらの応用は既に，脳神経外科領域を始めとした 様々な領域で活発に検討されている。手術シミュレータ は，コンピュータグラフィックス (CG) でモデル化した 手術対象部位の変形とそれに伴う反力を正確に計算し, リアルタイムに術部の描画や力覚の提示を行う必要があ る。しかしながら, 正確な変形を行うためには膨大な計 算量を要するため, 手術練習に必要な画質を保ちながら リアルタイム応答を実現するための様々な高速化手法が 求められている.

現在, 様々な臓器を対象とした手術シミュレータが

2008 年 8 月 5 日受付, 2008 年 12 月 2 日再受付, 2009 年 1 月 13 日探録 2007 年 12 月, 計測自動制御学会 SI 2007 にて発表 $\dagger$ 武蔵工業人学 人学院 工学研究科

( 1 158-8557 世田谷区玉堤 1-28-1, TEL 03-3703-3111)

† Graduate School of Engineering, Musashi Institute of Technology (1-28-1, Tamazutsumi, Setagaya, Tokyo 158-8557, Japan)
開発されている ${ }^{1) 4)}$. しかしながら，すべての手術に 共通する血管の変形と血管からの出血についてはあま り議論されてこなかった。そこで, 我々は人体内に多数 存在する血管の変形に対し，質点バネモデルを基にし た高速，かつ安定的な変形手法 ${ }^{5}$ を開発するとともに， SPH(Smoothed Particle Hydrodynamics) 法を基にした 流体シミュレーションを用いた出血表現の研究を行って きた ${ }^{6)}$.

しかし，これまでの研究では，術具が血管に触れた際 の血管表面形状に対する変形を考慮していなかった．血 管内部の血液状態を Navier-Stokes の方程式を用いた流 体シミュレーション7) で解析すれば，正確な流体の挙動 を表現できる反面，多大な計算時間がかかるためリアル タイム処理は困難である。また，格子ボルツマン法によ る流体シミュレーション 8)9 では格子問に生じる流体の 変化量を用いて，マクロ的に高精度な流体の挙動を解析 できるが，血管内の血液のように流体が変形する物体の 内部に含まれる場合には，格子間の計算が複雑になる問 題がある.

そこで，内部流体の局所的な流れを解析する代わりに， 血液が非圧縮性であることに注目して，血管の変形によ らず流体の体積を一定に保つことで流体の挙動をマクロ 的に表現し, 高速化を図る。本稿では, 血管内部の体積 を一定に保つために血管の内部に気体が存在するものと して，変形前後の体積差分に対してボイルの法則を用い て体積と内圧の関連付けを行い, 変形前の状態に内部圧 力を加えることで, 体積を一定に保ちながら安定した変 形を行う手法について述べる. 


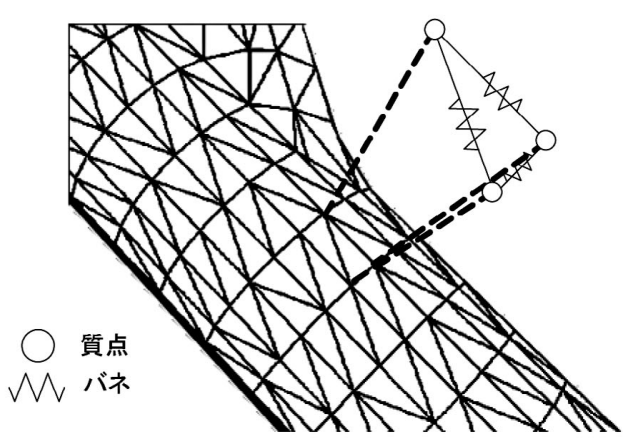

図 1 血管モデル

Blood vessel model.

\section{2. 血管モデル}

図 1 に示すように，血管の表面を三角形で分割し，三 角形の各頂点に質点, 各辺にバネを配置した質点バネモ デルを血管の表面モデルとする。ここで, 表面を質点と バネだけで構成したモデルでは，血管に外力を与えたと き, 血管の内部が存在しないため, 血管表面にのみ応力 が発生し, 血管の変形前後で体積が大きく変化する。こ

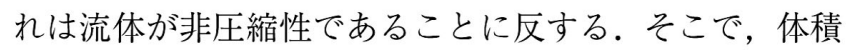
を一定に保つため血管の内部には一定の体積を持つ気体 が存在すると仮定し, 外力が加えられたとき，血管内部 に圧力が生じると考える.また，モデルのバネ係数 $k$ は, バネの自然長を $l_{0}$ とすれば, 血管のヤング率を $E$, 血 管の断面積を $S$ として, 歪みの定義とフックの法則より $k=\frac{E S}{l_{0}}$ となる.

\section{1 血管モデルの各要素内における釣合い}

二つの質点とそれを接続する一つのバネを要素として 要素内の静的釣合いの式を考える. 質点 $i$ の質量を $m_{i}$, 変位量を $\mathbf{u}_{\mathbf{i}}$, 外力を $\mathbf{f}_{\mathbf{i}}$, バネ係数を $k$ とし d'Alembert の原理 ${ }^{10)}$ より慣性力 $m_{i} \ddot{\mathbf{u}}_{\mathbf{i}}$ も外力として考えると, 要素 内の静的釣合いは次式 (1) で表される.

$$
\begin{aligned}
& k\left(\mathbf{u}_{\mathbf{2}}-\mathbf{u}_{\mathbf{1}}\right)=\mathbf{f}_{1}-m_{1} \ddot{\mathbf{u}}_{\mathbf{1}}+\mathbf{f}_{\mathbf{2}}-m_{2} \ddot{\mathbf{u}}_{\mathbf{2}} \\
& \mathbf{f}_{\mathbf{i}}=\mathbf{f}_{\mathbf{i}}^{\mathbf{c}}+\mathbf{f}_{\mathbf{i}}^{\mathbf{e}}+\mathbf{f}_{\mathbf{i}}^{\mathbf{p}}
\end{aligned}
$$

ただし, 外力 $\mathbf{f}_{\mathbf{i}}$ は術具と血管の接触による力 $\mathbf{f}_{\mathbf{i}}^{\mathrm{c}}$, バネ モデルの隣接要素間に働く力 $\mathbf{f}_{\mathrm{i}}^{\mathrm{e}}$, 血管の内部圧力による 力 $\mathbf{f}_{\mathbf{i}}^{\mathbf{p}}$ の和である. 次に, 各質点に扔ける仮想微小変位 を $\delta \mathbf{u}_{\mathbf{i}}$ としたとき，仮想仕事の原理より質点の仕事は

$$
\delta U=\left(\mathbf{f}_{\mathbf{1}}-m_{1} \ddot{\mathbf{u}}_{\mathbf{1}}\right) \delta \mathbf{u}_{\mathbf{1}}+\left(\mathbf{f}_{\mathbf{2}}-m_{2} \ddot{\mathbf{u}}_{\mathbf{2}}\right) \delta \mathbf{u}_{\mathbf{2}}
$$

となる。一方，バネの仕事は

$$
\delta W=k\left(\mathbf{u}_{\mathbf{2}}-\mathbf{u}_{\mathbf{1}}\right)\left(\delta \mathbf{u}_{\mathbf{2}}-\delta \mathbf{u}_{\mathbf{1}}\right)
$$

となり, 式(2) と式(3) は等しいから, 次式 (4) となる.

$$
\begin{aligned}
& \left\{\mathbf{f}_{\mathbf{1}}-m_{1} \ddot{\mathbf{u}}_{\mathbf{1}}+k\left(\mathbf{u}_{\mathbf{2}}-\mathbf{u}_{\mathbf{1}}\right)\right\} \delta \mathbf{u}_{\mathbf{1}} \\
& +\left\{\mathbf{f}_{\mathbf{2}}-m_{2} \ddot{\mathbf{u}}_{\mathbf{2}}-k\left(\mathbf{u}_{\mathbf{2}}-\mathbf{u}_{\mathbf{1}}\right)\right\} \delta \mathbf{u}_{\mathbf{2}}=\mathbf{0}
\end{aligned}
$$

ここで, 式 (4) は仮想微小変位の大きさに依存せず常 に成立するため次式 (5) となる。

$$
\left\{\begin{array}{l}
\mathbf{f}_{1}-m_{1} \ddot{\mathbf{u}}_{1}+k\left(\mathbf{u}_{2}-\mathbf{u}_{1}\right)=0 \\
\mathbf{f}_{2}-m_{2} \ddot{\mathbf{u}}_{2}-k\left(\mathbf{u}_{2}-\mathbf{u}_{1}\right)=0
\end{array}\right.
$$

また，式 (5) をマトリックス表示すると次式 (6) とな り要素内の釗合い関係式が得られる.

$$
\begin{aligned}
\left\{\begin{array}{l}
\mathbf{f}_{1} \\
\mathbf{f}_{2}
\end{array}\right\} & =\left[\begin{array}{cc}
m_{1} & 0 \\
0 & m_{2}
\end{array}\right]\left\{\begin{array}{l}
\ddot{\mathbf{u}}_{1} \\
\ddot{\mathbf{u}}_{2}
\end{array}\right\} \\
& +\left[\begin{array}{cc}
k & -k \\
-k & k
\end{array}\right]\left\{\begin{array}{l}
\mathbf{u}_{1} \\
\mathbf{u}_{2}
\end{array}\right\}
\end{aligned}
$$

\section{2 血管モデルの系全体における釣合い}

モデル全体の釣合いは，要素毎の釣合い関係式を重ね 合わせることで得られる。このとき，隣接質点間に働く 外力 $\mathbf{f} \mathbf{e}$ の総和は作用反作用の原理から 0 となる。たた し, 要素毎にバネの傾きが異なるため, 系全体の座標と してワールド座標系を用いる。 ワールド座標系からロー カル座標系への変換行列を $\mathbf{R}$, ワールド座標系での外力 および質点の変位を $\mathbf{F}$ および $\mathbf{U}$ とすると, 式 (6)より 次式 (7) が得られる。ただし，M は対角行列であるから $\mathbf{R}^{-1} \mathbf{M R}=\mathbf{M}$ となる。なお，図 $\mathbf{2}$ において $(\xi, \eta, \zeta)$ を ローカル座標系, $(x, y, z)$ をワールド座標系とする.

$$
\left\{\begin{array}{l}
\mathbf{F}=\mathbf{R}^{-1} \mathbf{K R U}+\mathbf{M} \ddot{\mathbf{U}} \\
\mathbf{F}=\mathbf{F}^{c}+\mathbf{F}^{p}
\end{array}\right.
$$

また，質点の運動エネルギーは速度に比例して減衰す るものと考え，減衰マトリックス $\mathbf{C}$ を式 (7) に追加する と, 運動方程式は次式 (8) となる.

$$
\mathbf{F}=\mathbf{R}^{-1} \mathbf{K R U}+\mathbf{C} \dot{\mathbf{U}}+\mathbf{M} \ddot{\mathbf{U}}
$$

\section{3. 内部流体の圧力変化}

血液は非圧縮性流体であるから体積は変化しない。し たがって，外力により各質点の位置が変位したとき，血 管の内部圧力を加えて体積を一定に保つように補正する 必要がある。

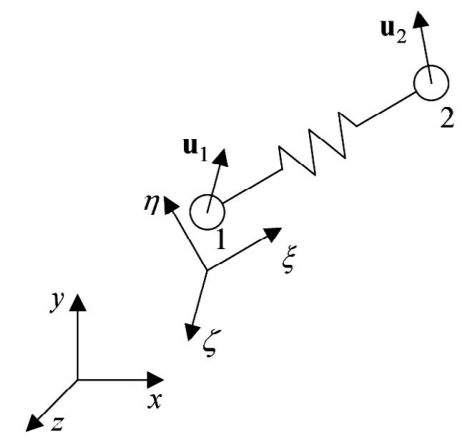

図 2 系全体の座標系 Coordination in the system. 
本稿では, 血液の体積を一定に保つため, 気体に対す る体積と圧力の関係式であるボイルの法則を用いる。ボ イルの法則では気体の内部状態と温度が一定のとき, 圧 力 $P$ と体積 $V$ の積 $P V$ は一定となる.ここで, 1 回の 変形処理に対して数回の繰り返し計算を行う. $n$ 回目の 繰り返しにおいて, 変形前の圧力を $P_{0}$, 体積を $V_{0}$, 変 形後の圧力を $P_{n}$, 体積を $V_{n}$ とすれば, 変形後の圧力は ボイルの法則より次式 (9) となる.

$$
P_{n}=\frac{P_{0} V_{0}}{V_{n}}
$$

ただし, 変形前の圧力 $P_{0}$ と変形後の圧力 $P_{n}$ の差分圧 力 $\left(P_{0}-P_{n}\right)$ を質点への外力に加算し, 再度, 変形計算 を行うことで体積変化を小さくし, 体積を一定に保つ.

ここで, 血管内部の体積はガウスの発散定理を用いる ことで, 表面のメッシュ情報から簡単に計算することが できる.ガウスの発散定理は, 任意のベクトル場を $\mathbf{A}$, 表面の単位法線ベクトルを $\mathbf{n}$ とすると, 次式 (10) で表 される。

$$
\int_{V} \operatorname{div} \mathbf{A} d V=\int_{S} \mathbf{A} \cdot \mathbf{n} d S
$$

ここで， $\operatorname{div} \mathbf{A}=1$ となるベクトル $\mathbf{A}$ を用いれば体積 $V$ は次式 (11) となる.

$$
V=\int_{S} \mathbf{A} \cdot \mathbf{n} d S
$$

血管表面を構成する各三角メッシュの面積は，三角形 を構成する 2 辺のベクトル積から求まり, 法線の向きは ベクトル積の向きである．三角メッシュ上にある任意の 三角形 $i$ を構成する 2 辺のベクトルをそれぞれ $\mathbf{a}_{\mathbf{i}}$ および $\mathbf{b}_{\mathbf{i}}$ とすると, 式 (11) を離散化した式 (12) で体積が求め られる。

$$
V=\sum_{i=1}^{T} \mathbf{A}_{i} \cdot\left(\frac{\mathbf{a}_{i} \times \mathbf{b}_{i}}{2}\right)
$$

ただし， $T$ は三角メッシュの総数である。ここで，血 管表面は微小三角形から構成されているため, ベクトル 場 $\mathbf{A}_{i}$ の位置 $\left(x_{i}, y_{i}, z_{i}\right)$ は, 各三角形の重心座標で近似 できる。

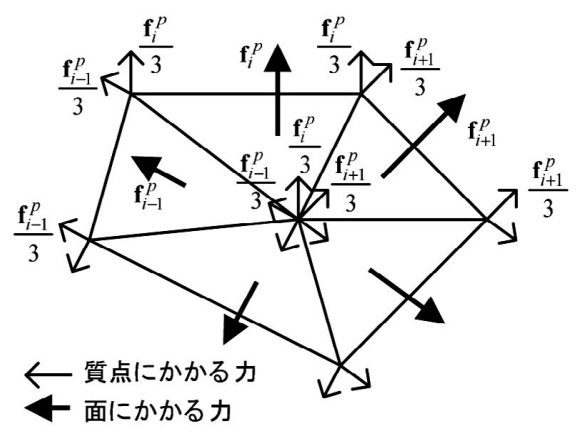

図 3 質点に与える内部圧力 Inside pressure at each vertex.
次に, 各質点にかかる力を計算する. パスカルの原理 より, 液体表面にかかる外力は, 溶液全体に等しくかか るため, 血管モデルを構成する各三角形 $i$ に加わる力は 内部圧力を $P$ とすると $\mathrm{f}_{i}^{p}=P \mathrm{~S}_{i}$ である. 次に, 三角形 $i$ にかかる力 $\mathbf{f}_{i}^{p}$ を三角形 $i$ の構成要素 (質点) に均等に分 散して， $\frac{\mathbf{f}_{i}^{p}}{3}$ とすると，質点 $j$ にかかる力 $\mathbf{F}_{j}^{p}$ は質点 $j$ を 頂点に持つ各三角形 $i$ からの合力となり, 次式 (13) で表 される.

$$
\mathbf{F}_{j}^{p}=\sum_{i=1}^{T^{\prime}} \frac{\mathbf{f}_{i}^{p}}{3}
$$

ただし， $T^{\prime}$ は頂点 $j$ を構成する三角形の数である.

\section{4. 血管変形計算}

手術シミュレータでは血管の変形状態をリアルタイム に表示する必要がある。そこで本稿では，陰解法に比べ て高速な計算が可能な陽解法によるシミュレーションを 行う。ただし，変形計算は体積を一定に保つために， 1 回の変形処理あたり $N$ 回の繰り返し計算を行い, 圧力 を逐次調整する。ここで, 時刻 $t$ における $n$ 回目の繰り 返し計算の運動方程式 (8) を次式 (14) とする。これを中 心差分法により, 速度と加速度を時刻 $t+\Delta t$ と $t-\Delta t$ の変位で表して式 (15) を式 (14)へ代入すると式 (16) と なる。

$$
\begin{aligned}
& { }^{t} \mathbf{F}^{c}+{ }^{t} \mathbf{F}_{(n)}^{p}={ }^{t} \mathbf{R}^{-1 t} \mathbf{K}^{t} \mathbf{R}^{t} \mathbf{U}+\mathbf{C}^{t} \dot{\mathbf{U}}+\mathbf{M}^{t} \ddot{\mathbf{U}}(14) \\
& \left\{\begin{array}{l}
{ }^{t} \dot{\mathbf{U}}=\frac{1}{2 \Delta t}\left({ }^{t+\Delta t} \mathbf{U}-{ }^{t-\Delta t} \mathbf{U}\right) \\
\left.{ }^{t} \ddot{\mathbf{U}}=\frac{1}{\Delta t^{2}}{ }^{t+\Delta t} \mathbf{U}-2^{t} \mathbf{U}+{ }^{t-\Delta t} \mathbf{U}\right)
\end{array}\right. \\
& \left(\frac{1}{\Delta t^{2}} \mathbf{M}+\frac{1}{2 \Delta t} \mathbf{C}\right)^{t+\Delta t} \mathbf{U}= \\
& { }^{t} \mathbf{F}^{c}+{ }^{t} \mathbf{F}_{(n)}^{p}-{ }^{t} \mathbf{R}^{-1 t} \mathbf{K}^{t} \mathbf{R}^{t} \mathbf{U} \\
& +\frac{1}{\Delta t^{2}} \mathbf{M}\left(2^{t} \mathbf{U}-{ }^{t-\Delta t} \mathbf{U}\right)+\frac{1}{2 \Delta t} \mathbf{C}^{t-\Delta t} \mathbf{U}
\end{aligned}
$$

ここで, 内部圧力による力 ${ }^{t} \mathbf{F}_{(n)}^{p}$ は式 (13) より求める. また, $n$ 回目の繰り返し計算における内部圧力は, 式 (9) より求める. 以上の計算を繰り返し，体積変化が微小に なったとき計算を終了する.

\section{5. シミュレーション結果}

本来は血管の物理的特性を考慮して血管モデルを作 成する必要があるが，本研究は手術シミュレータとして のリアルタイム性を重視した血管の変形を目的として いるため, 血管モデルは単純な弾性体とした。 また, 脳 動脈瘤のクリップ手術を対象として, 半径 $3 \mathrm{~mm}$ の血管 モデル (質点数 602 , バネ数 1,800 ) をモデリングソフト を用いて作成し，500 ステップの間，質点に外力 (引張 荷重)を加えて, 弾性変形により元の形状に戻るまでの 体積変化量を測定した。測定に使用した PC は, CPU 


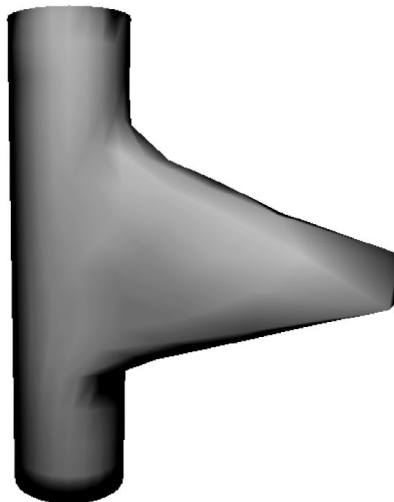

(a) 体積補正なし

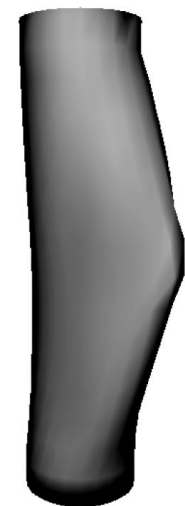

（b）体積補正あり
図 4 血管の変形比較 Comparison of blood vessel deformations.

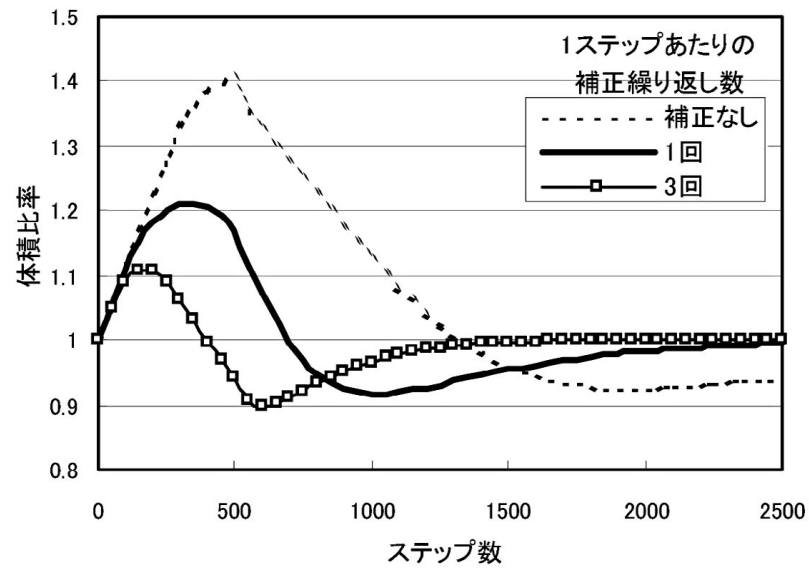

図 5 変形時の体積変化

Volume transition for deformation.

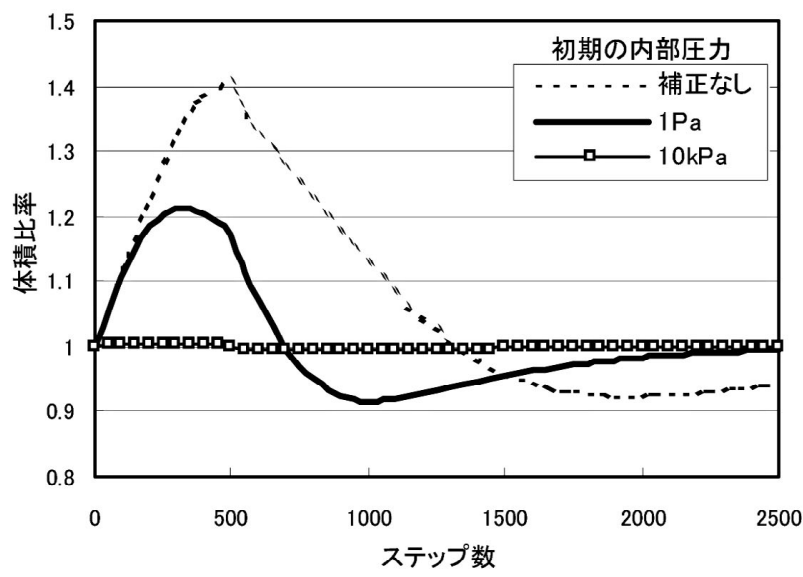

図 6 内部圧力毎の体積変化

Volume transition for deformation in inside pressure.

PentiumD 3GHz, Memory 2GB, GeForce8600GT を搭 載している. 図 4 に，体積補正なしの場合 (a) と体積補 正ありの場合 (b) の変形の状態を示す. 外力による血管 の形状変化に伴い，体積は変化するが，図 5 に示すよう に体積補正ありの場合, 繰り返し数を増やすと精度が向 上し，体積が一定に保たれていることが判る。また，図

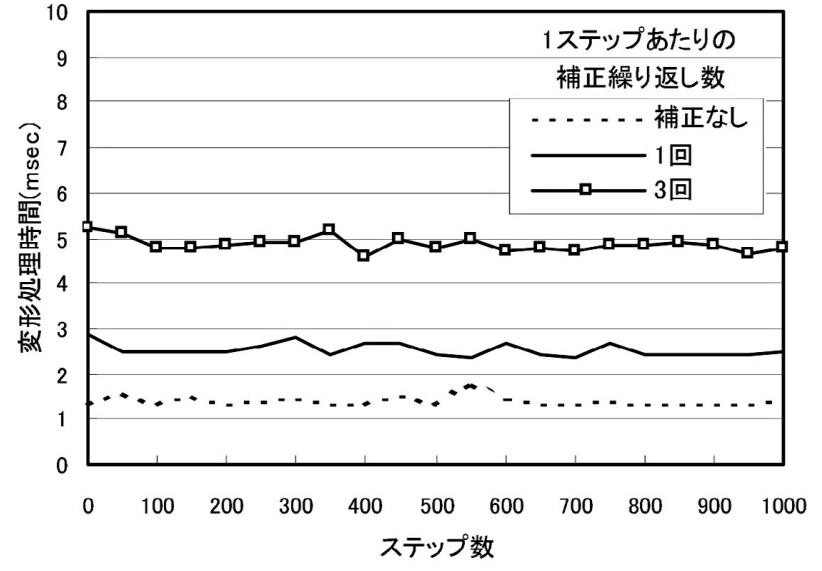

図 7 変形計算洔間

Calculation time for deformation.

6 は，補正繰り返し数を 1 回として，初期の内部圧力を 変化した場合の体積補正精度を示す。内部圧力が高いほ ど，繰り返し毎の体積の補正が大きくなり，1回の繰り返 し数でも体積は高精度で一定に保たれていることが判る. また，体積の補正を行った場合の変形計算時間を図 7 に 示す. 図 7 より, 変形処理時間は, 1 ステップあたりの繰 り返し回数に比例する。したがって，本手法の計算量は 質点数を $n$ とすると $O(n)$ となる。一方, Navier-Stokes の方程式を用いた場合，ガウスの消去法により連立方程 式を解くものとすれば計算量は $O\left(n^{2}\right)$ であることから, 本手法の方が高速である.

\section{6. むすび}

本稿では，血管内部にある血液を考慮にした血管表 面の変形を高速に行うために，気体に対するボイルの 法則を用いて，血管内部の体積を一定に保つ手法を提 案した。本手法では，血管内部をマク口的に扱うため, Navier-Stokes の方程式を用いた于法に比べて高速な変 形計算が可能である．本手法では，体積を一定に保つた めに繰り返し計算を必要とするが，1 回の繰り返し数で も高い精度で体積を一定に保つことができ, 質点数 602, バネ数 1,800 の血管モデルに対して, OpenGLによる描 画を含めてリアルタイム処理 (60FPS) が可能であった. 本稿では，気体を基にした血管の変形について検討した が，今後は気体と流体の差を考慮した変形と，血管の物 理的特性を持つモデルを構築し血管の伸縮性や限界，レ オロジー等を考慮した，より正確で信頼性の高い血管の 変形手法について検討する予定である。また，出血表現 を実現するために，Navier-Stokes の方程式を基にした 粒了法を基本としながら GPUによる並列処理や, 部分 的に本稿のマクロ的手法を用いることでリアルタイム化 の検討を行う予定である。 


\section{〔文献〕}

1）甲悲慎也，内山明彦，川上憲司，高津光洋，鈴木直樹，“手術計画システムのた めの臟器モデル”, MEDICAL IMAGING TECHNOLOGY, 14, 4, pp.475-476 (1996)

2）鈴木直樹, 服部麻木, 江積剛, 熊野宣弘, 池本明犬, 足立吉隆, 高津光洋, “触 覚を伴った手術作業が可能なバーチャル手術システムの開発”,TVRSJ, 3 , 4, pp.237-243 (1998)

3）向井信彦, 原田雅之, 室井克信, 宮本裕二, 浦谷明宏, 矢野徹 “ $\mathrm{PC}$ ベースリア ルタイム手術シミュレータの開発”, 信学論, J84-D-II, 6, pp.1213-1221 (2001)

4) 山本恭弘, 中尾恵, 黒田知宏, 小山博史, 小森優, 松田哲也, 坂口元一, 米田 正始, 高橋隆,“心臓血管外科に打ける拍動を伴う大動脈触診シミュレーショ ンシステム”, 電学論 $\mathrm{E}, \mathbf{1 2 3}, 3, \mathrm{pp} .85-91$ (2003)

5）向井信彦，阿部信吾，小杉信, “手術シミュレー夕向け血管変形の安定化手 法”,TVRSJ, 11, 1, pp.181-188 (2006)

6）向井信彦，西村律朗，小祄信,“手術シミュレータ向け出血表現の高速化手 法”,TVRSJ, 11, 3, pp.371-376 (2006)

7) J.Stam, "Stable Fluids", SIGGRAPH99, pp.121-128 (1999)

8) X.Wei, W.Li, K.Mueller, A.Kaufman, "The Lattice-Boltzmann Method for Gaseous Phenomena", IEEE Transactions on Visualization and Computer Graphics10(2), pp.164-176 (2004)

9) Wei Li, ZbeFan, Xiaoming Wei, Arie Kaufman,“複雑な境界を持つ 流れのシミュレーション”, GPUGems2, pp.687-701 (2005)

10）日本塑性加工学会編,“非線形有限要素法”, コロナ (1994)

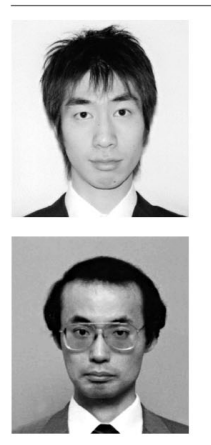

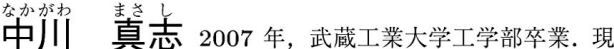
在, 同大大学院博士前期課程在学中. コンピュータグラフィッ クスを用いた物理シミュレーションに興味を持つ.

简架信䇾 1985 年, 大阪大学大学院基礎工学研究 科博士前期㗚程修了. 同年, 三菱電機 (株) 入社. 1997 年, コーネル大学大学院コンピュータサイエンス学科修士課程 修了. 2001 年, 大阪大学大学院基砒工学研究科博士後期課 程修了 (工学博士). 2002 年, 武蔵工業大学工学部助教授。 2007 年, 同大学知識工学部教授, コンピュータグラフィッ クスおよびバーチャルリアリティに関する研究に従事．正 会員.

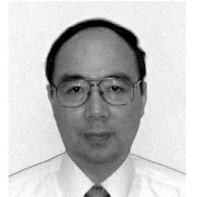

小榜信 1970 年, 東京工業大学大学院修士課 程修了。同年, 日本電信電話公社 (現 NTT) 入社. 1980 年, 東京工業大学上り博士号取得 (工学博士). 同年, 西ト イツ郵電省研究所客員研究員. 1994 年, 武蔵工業大学工学 部教授. 2007 年, 同大知識工学部教授、画像処理およびさ ンピュータグラフィックスに関する研究に従事. 正会員. 